\title{
Does the American mink displace the European polecat? A need for more research on interspecific competition between invasive and native species
}

\author{
Marcin Brzeziński ${ }^{1}$ D $\cdot$ Aleksandra Zarzycka ${ }^{1} \cdot$ Tom A. Diserens $^{2,1} \cdot$ Andrzej Zalewski $^{2}$ (D)
}

Received: 15 April 2021 / Revised: 22 June 2021 / Accepted: 23 June 2021 / Published online: 2 July 2021

(c) The Author(s) 2022, corrected publication 2022

\begin{abstract}
Introduced alien species can negatively affect native competitors by reducing their populations or eliminating them from ecosystems. However, studies do not always find evidence for anticipated impacts, and changes in native populations can be difficult to estimate. Interactions between the invasive American mink Neovison vison and native European polecat Mustela putorius have been studied in several countries, but the mink's impact on polecat populations at a large spatiotemporal scale remains unclear. In the years 1995-2018, we live-trapped mink and polecats at 60 study sites in Poland, and we analysed hunting bags of mink and polecats from the years 2009-2018. During 13,766 trap-nights, we captured 905 individuals. Mink comprised $91.2 \%$ and polecats $8.8 \%$ of trapped animals. The mean mink and polecat trappability was 6 and 0.6 individuals per 100 trap-nights, respectively. At rivers, polecat and mink trappability were negatively correlated, whereas at lakes, they were not correlated. The sex ratio of trapped polecats was more skewed toward males than that of mink. Mink comprised $63.6 \%$ and polecats $36.4 \%$ of 59,831 animals killed by hunters. Over 10 years, the numbers of mink shot annually increased slightly, whereas the numbers of polecat decreased slightly. There was a positive correlation between numbers of mink and polecats shot annually. We found weak evidence that at a large spatiotemporal scale, the invasion of mink has led to a decline in polecat numbers. Although the datasets we analysed were based on large samples, they were insufficient to show evidence of competitive interactions between these two mustelids.
\end{abstract}

Keywords Mustelids $\cdot$ Population $\cdot$ Trapping $\cdot$ Hunting bag records

\section{Introduction}

One of the fundamentals in ecology predicates that species can co-exist in a community if they at least partly segregate their ecological niches (Pianka 1974). In natural and stable

Marcin Brzeziński

marcinb@biol.uw.edu.pl

Aleksandra Zarzycka

a.zarzycka@biol.uw.edu.pl

Tom A. Diserens

tdiserens@ibs.bialowieza.pl

Andrzej Zalewski

zalewski@ibs.bialowieza.pl

1 Faculty of Biology, University of Warsaw, ul. Miecznikowa 1, 02-097 Warszawa, Poland

2 Mammal Research Institute, Polish Academy of Sciences, ul. Stoczek 1, 17-230 Białowieża, Poland communities, this segregation is established over a long period of co-evolution. Human-made disturbances, such as introductions of non-native species, interfere with ecosystem equilibriums and can cause the ecological niches of native species to change in response to competition and predation from new members of a community (niche displacement). If native species cannot adapt to the presence of new competitors or predators, their populations can decrease or even be eliminated from an ecosystem (Hardin 1960; Salo et al. 2007; Doherty et al. 2016).

As between native species, competition between invasive and native species with overlapping ecological niches is based on resource exploitation or interference between individuals (Polo-Cavia et al. 2011; Peck et al. 2014; Le Louarn et al. 2016). Regardless of the mechanisms behind it, competition may be lower in complex environments with high resource availability, and in such contexts, the negative impact of an invasive competitor can be negligible. Indeed, some invasive and native species of the same guild have 
considerable dietary overlap and can coexist in an ecosystem (Bertolino et al. 2009; Zalewski et al. 2021a). Competition from invasive species can cause extinction of native species at local scales but unlike predation seldom causes global extinction (Sax et al. 2007). On the other hand, the scientific literature probably underestimates how often invasive and native species coexist over long periods, as it is easier to show (publish) that an invasive species has a negative impact on a native species than to find evidence of no effect.

In Europe, the American mink Neovison vison is a widespread invasive mammalian species (Bonesi and Palazon 2007). Its competitive impact on native carnivores, mostly the Eurasian otter Lutra lutra and European mink Mustela lutreola, has been studied across the continent (Sidorovich et al. 1999, 2010; Jędrzejewska et al. 2001; Bonesi et al. 2004; Brzeziński et al. 2008). There have also been attempts to explain how the American mink interacts with the European polecat Mustela putorius (Lodé 1993; Hammershøj et al. 2004; Fournier et al. 2007; Harrington and Macdonald 2008; Barrientos 2015), although its impact on polecat populations at a landscape scale remains unclear. The American mink may be a driver of polecat decline (e.g., Sidorovich et al. 2008; Melero et al. 2012), but it has proven difficult to determine the long-term consequences of interspecific competition between the two species (both interference competition and exploitation competition for food and space can occur). The ecological niches of the native polecat and invasive American mink largely overlap: the species often share riparian habitats (Harrington and Macdonald 2008) and partly exploit the same food resources (Sidorovich 2000; Zalewski et al. 2021a). They are both opportunistic predators, but the mink is a food generalist, whereas the polecat is more specialized (Weber 1989a; Jędrzejewska et al. 2001; Zalewski et al. 2021a). The most significant differences in their diets concern aquatic prey (fish and crayfish), commonly hunted by the mink but rarely by the polecat (Sidorovich 2000; Hammershøj et al. 2004). However, the latter's diet can display high geographic, environmental and seasonal variation (Lodé 1993; Weber 1989a, b; Lodé 1997; Sidorovich 2000; Lanszki and Heltai 2007; Santos et al. 2009; Malecha and Antczak 2013), suggesting the species can adapt to varying availability of food resources. Moreover, the polecat is flexible in its choice of habitat, which is mostly affected by the availability of food (Jędrzejewski et al. 1993; Lodé 1994) and/or resting sites (Weber 1989c). In general, polecats select areas of high habitat diversity (Zabala et al. 2005). They often inhabit the vicinity of waterbodies but also other habitats, distant from aquatic ones (Fournier et al. 2007). Polecats easily move between anthropogenic and non-anthropogenic habitats, and these movements usually occur seasonally (Weber 1989c; Brzeziński et al. 1992; Baghli et al. 2005). In some regions, the species is associated with human-modified environments (including settlements); however, polecat populations also exist in areas of low human population density (Virgós 2003). In contrast, the American mink is more restricted to riparian habitats (Lodé 1993; Harrington and Macdonald 2008; Melero et al. 2008; Brzeziński et al. 2010b) and avoids human settlements (Brzeziński et al. 2012, 2018; Ahlers et al. 2016). Little is known about how the two species compete for dens. Mink occupy dens close to the shoreline, whereas polecats prefer shelters further away from waterbodies (Harrington and Macdonald 2008). Thus, in areas where these species occur sympatrically, their food and habitat niches can overlap but can also be distinct.

The polecat's population dynamics in Europe remain largely unknown. Demographic analyses of local populations come from a variety of sources, such as records of road casualties and sightings (Melero et al. 2012; Berzins and Ruette 2014; Croose 2016), winter tracking (Sidorovich et al. 2008) and national hunting records (Baghli and Verhagen 2003). However, in general, the existing knowledge is mostly based on sparse data, and recent reviews may have been misleading due to being based on unreliable information (Hofmeester et al. 2019). In most countries where trends have been identified, the polecat population is known or suspected to be declining (Croose et al. 2018). As polecat populations are subject to a variety of positive and negative factors, some opposing trends probably occur locally, making large-scale analyses of population dynamics difficult. Consequently, most recent national reports on the polecat's status recommend the deployment of new studies to reveal population trends in more detail (Berzins and Ruette 2014; Costa et al. 2014). The UK's recent national survey contrasts with the general declining trend as it revealed an increase and geographical expansion of the polecat in the last decades (Sainsbury et al. 2019); however, it should be pointed out that British population is recovering in its former range.

Competition with mink is one of the many environmental factors that can negatively affect polecat populations. It is widely believed that polecats are vulnerable to several anthropogenic activities, such as traffic, changes in agricultural landscapes, drainage of wetlands, poisoning, hunting etc. (Blandford 1987; Shore et al. 1999; Sainsbury et al. 2018). Some of these factors affect the polecat population directly by increasing mortality, others indirectly by reducing food availability, for example, by decreasing amphibian and bird abundance or limiting access to livestock. In some regions of Europe (UK, Spain), polecat population sizes mostly depend on the density of wild rabbits Oryctolagus cuniculus (Santos et al. 2009; Sainsbury et al. 2019), a staple food of polecats (Roger 1991; Santos et al. 2009). At local scales, polecat populations can depend on other prey, for example water voles Arvicola amphibius, and they can also vary with the vole cycle (Weber et al. 2002). 
In Poland, the polecat is distributed all over the country, and its geographical range has remained stable over the last decades (Pucek and Raczyński 1983; Institute of Nature Conservation PAS 2010), whereas the American mink has extended its range since the end of 1970s, nowadays inhabiting about $75 \%$ of the country (Brzeziński et al. 2019). After its invasion, densities of local mink populations increased gradually and reached their maximum between 10 and 15 years after colonization of an area (Brzeziński et al. 2019). Studies on the consequences of the mink expansion in Poland have mainly focused on its predatory impact on native prey, mainly waterbirds and semi-aquatic mammals (Brzeziński et al. 2010a, 2012, 2018, 2020; Niemczynowicz et al. 2017). A few studies have reported the mink's interactions with native carnivores, e.g., with otter and polecat (Brzeziński et al. 2008, 2010b; Zalewski et al. 2021a); however, we still lack quantitative analyses of their population trends in areas invaded by mink. In this study, we analysed data from mink live-trapping, conducted in Poland over more than 20 years (1995-2018) and hunting records from a 10-year period (2009-2018). We used the live-trapping data to compare mink and polecat densities in riparian habitats, and we used the hunting records to analyse the population trends of both species and their relative abundances in various parts of the country. We hypothesized that if mink competition affected polecat densities, the numbers of polecats hunted in areas colonized by mink should have declined compared to areas where the mink is absent. We discuss the results in the context of the existing knowledge on polecatmink interactions and suggest future research directions.

\section{Materials and methods}

\section{Live-trapping}

We calculated density indices of mink and polecat populations in Poland on the basis of live-trapping carried out in the years 1995-2018. Animals were trapped during various projects studying mink biology, during which mink were caught intentionally and polecats unintentionally. Trapping was conducted at 60 study sites: at 50 rivers and 10 lakes. Trapping sites were distributed across the whole of Poland (Fig. 1; Appendix). We caught animals during only a single

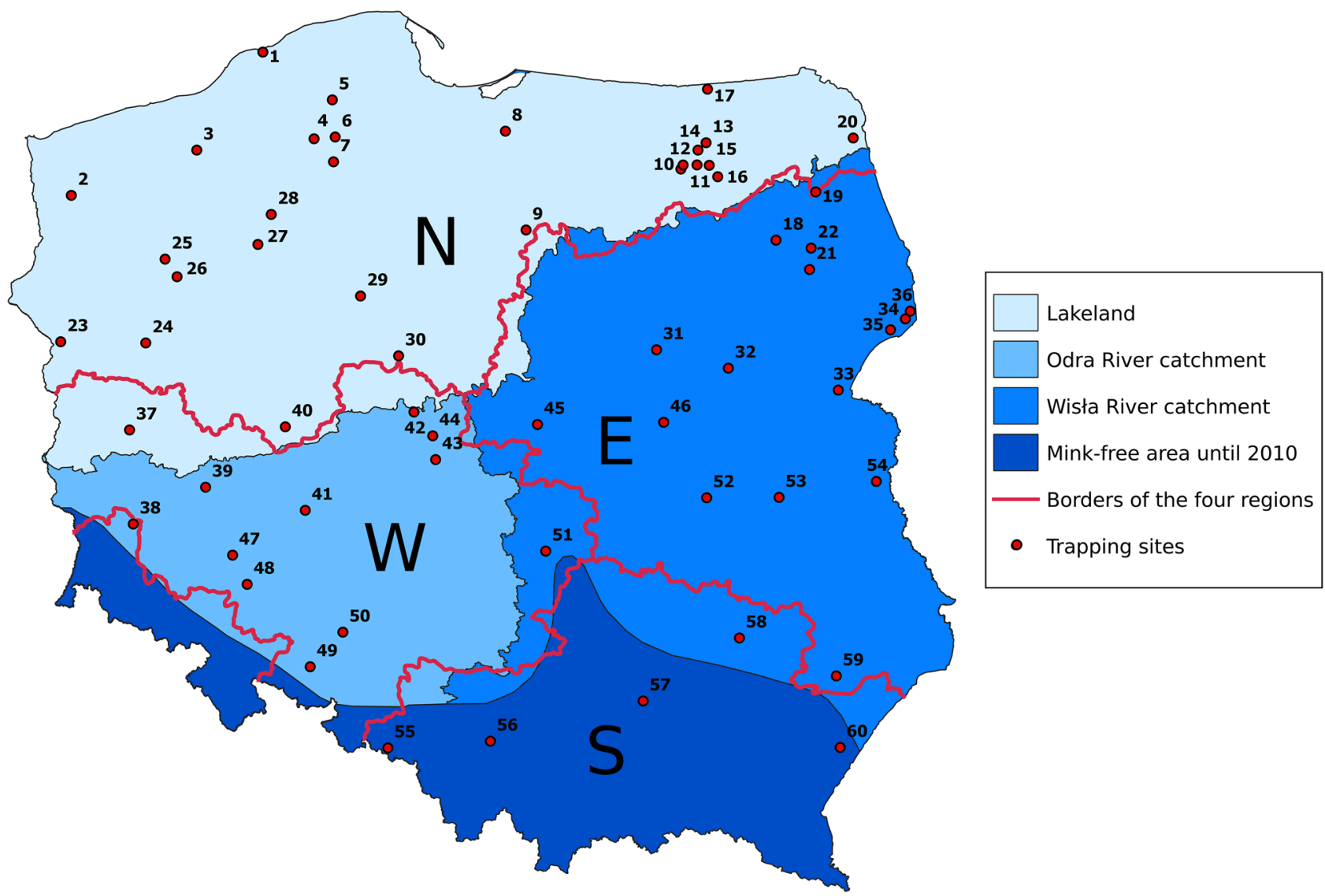

Fig. 1 Location of trapping sites and division of Poland into four regions. Numbers on the map correspond to the study site numbers in Appendix 
trapping session at 41 sites, and during more than one at the rest. The total trapping effort was 140 trapping sessions and 13,766 trap-nights. Animals were live-trapped in autumn (November-December), winter (January-February) and spring (March-April). Wooden-box or wire-mesh live-traps baited with fresh fish were set at about 500-m intervals along shorelines and checked once a day. Captured mink and polecats were marked, weighed and released at the location of their capture. The sex of individuals of both species was determined. At each study site, at least 15 traps were used during each trapping session. The duration of trapping sessions at particular sites and years varied considerably, from 4 to 14 days. To compare polecat and mink densities at various study sites, we calculated the index of animal trappability (number of individuals trapped per 100 trap-nights) during the first 4-5 days of trapping session. All animal capture and handling procedures were approved by the Ministry of Environment, Regional Directorate for Environmental Protection and Local Ethics Committee for Animal Experiments.

\section{Factors affecting polecat trappability}

The effects of mink density, season and habitat variables on the number of the polecats trapped was analysed with generalized mixed linear models (GLMMs) with Poisson distribution in the 'Ime4' package in $\mathrm{R}$ (version 4.0.2, $\mathrm{R}$ Core Team 2020). The models included four explanatory variables: the number of mink trapped per 100 trap-nights, time (years) that had elapsed since mink colonized a site (see Brzeziński et al. 2019), water body type (river or lake) and season (autumn, winter and spring). We also included the interaction between the number of mink trapped per 100 trap-nights and water body type, assuming that the number of trapped polecats could vary at rivers and lakes in relation to index of mink density. The total number of polecats trapped varied in relation to the number of trap-nights; therefore, we used trap-nights as an offset to keep the response variable independent of the variation in sampling effort. We also included the trapping site ID as a random factor. We excluded from the analysis ten sites where no polecats or mink were captured.

\section{Hunting bag records}

To compare relative abundances of the polecat and American mink in various regions of Poland, hunting bag records from 49 hunting districts covering the entire country were obtained from the Polish Hunting Association. The numbers of hunted polecats and mink were analysed for the period 2009-2018. We divided Poland into four regions and assigned hunting districts to each of them (Fig. 1). Region "North" (13 districts) comprises a lakeland, the region of Poland with the highest number of aquatic habitats, colonized by mink before the other regions (colonization started here in early 1980s) (Brzeziński et al. 2019). Region "South" (12 districts) comprises an area that had no mink or very low mink densities prior to 2010 (Brzeziński et al. 2019). This region is mostly covered by the Sudetes and Carpathian Mountains and their foothills. Regions "West" (11 districts) and "East" (13 districts) comprise Polish lowlands and encompass the basins of the country's two largest rivers, the Oder in the west and Vistula in the east (although the parts of the river basins that overlap with the "North" and "South" regions were excluded from the regions "West" and "East"). Most of western and eastern Poland was colonized by mink between 1990 and 2010. The borders of the lakeland, river catchments and mink range correspond approximately to the borders of hunting districts allowing us to assign the data from various sources into same regions.

Hunting bags of the polecat and mink were compared between the four regions. We also estimated mean trapping success of mink and polecats in the four regions by assigning all trapping sites to one of them and compared polecat-mink proportions from live-trapping and hunting bag records.

\section{Results}

\section{Polecat and mink trappability}

Polecats comprised $8.8 \%$ and mink $91.2 \%$ of animals captured in the years 1995-2018 (Fig. 2a). The polecat's mean trappability was 0.6 individuals per 100 trap-nights, and the mink's was 6 individuals per 100 trap-nights. The highest recorded index of polecat density was much lower (5.6 individuals/100 trap-nights) than the highest index of mink density (20.2 individuals/100 trap-nights). No polecats or mink were trapped in southern Poland. In other regions, mean polecat trappability ranged from 0.2 to 0.7 individuals per 100 trap-nights, and mean mink trappability ranged from 5.7 to 6.4 individuals per 100 trap-nights (Fig. 2b). In these three regions, the proportions of captured polecats and mink did not differ significantly (chi-square test: $p>0.05$ ) (Fig. 2b).

No polecats and mink were trapped during 10 trapping sessions (7.1\%); half of them took place in southern Poland, four in western and one in northern region. In five trapping sessions, we captured only polecats $(3.6 \%)$; in 87 trapping sessions, only mink (62.1\%), and in 38 of them, we captured both species $(27.2 \%)$. There were only seven trapping sessions during which polecats were trapped more frequently than mink, whereas mink were trapped more frequently than polecats in 122 trapping sessions.

The number of captured polecats was highest in autumn and lowest in spring (Fig. 3a; Table 1), and was related to water body type (lower at rivers and higher at lakes). At 

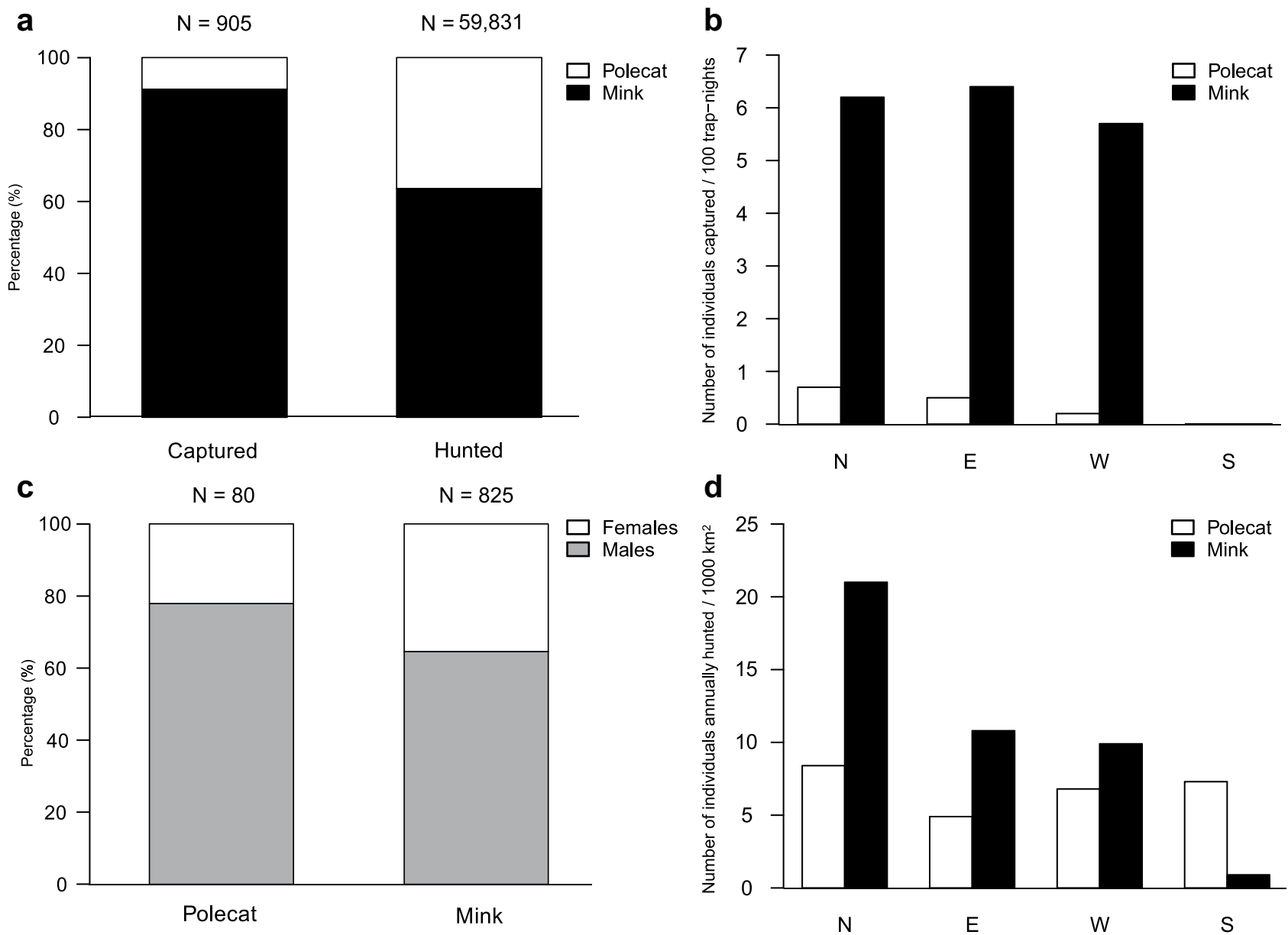

Fig. 2 Proportion of polecats and mink trapped and killed by hunters (a), number of polecats and mink captured per 100 trap-nights (b), sex ratio of trapped polecats and mink (c), number of polecats and mink annually killed by hunters per $1000 \mathrm{~km}^{2}(\mathbf{d})$

rivers, the number of captured polecats decreased with increasing index of mink density (number of mink captured per 100 trap-nights), whereas at lakes, no such correlation was observed (Fig. 3b; Table 1). The number of captured polecats did not change with time that has elapsed since mink colonized a given study area; however, an increasing trend was recorded (Fig. 3c; Table 1).

The sex ratio of trapped animals differed between the species (chi-square test: $p<0.05$ ) (Fig. 2c). Males comprised $77.9 \%$ and $64.6 \%$ of captured polecats and mink, respectively.

\section{Hunting bag records}

In the years 2009-2018, hunters shot 21,783 (36.4\%) polecats and 30,048 (63.6\%) mink (Fig. 2a). Only in southern Poland were polecats shot more often than mink $(89.5 \%$ vs $10.5 \%$, respectively) (Fig. 2d). Across the whole country, hunters shot 7 polecats $/ 1000 \mathrm{~km}^{2} / y e a r$ and 12.2 mink/1000 $\mathrm{km}^{2} /$ year, on average. Across the four regions, the number of polecats killed ranged from 4.9 individuals $/ 1000 \mathrm{~km}^{2} /$ year in region "East" to 8.4 individuals $/ 1000 \mathrm{~km}^{2} /$ year in region North. Mink were shot most often in region North (21 individuals $/ 1000 \mathrm{~km}^{2} /$ year), half as often in regions "West" and "East" (about 10 individuals/1000 km²/year) and only occasionally in region "South" (0.9 individuals $/ 1000 \mathrm{~km}^{2} /$ year) (Fig. 2d). Polecats and mink were shot at different proportions in the four regions of Poland. Although there were no differences in the proportions of polecats and mink shot in regions "North", "West" and "East" (chi-square test: $p>0.05$ ), the region "South", where very few mink were shot, had the opposite proportion to the other regions (chisquare test: $p<0.001)$. Across the whole country, polecats and mink were hunted at different proportions than they were trapped (chi-square test: $p<0.001$ ) (Fig. 2a).

Over the 10 years, the numbers of mink shot annually increased slightly, whereas those of polecats decreased slightly. The annual mink hunting bag increased most significantly in region "East" (Fig. 4). The most negative trend in the number of hunted polecats was recorded in region 
a

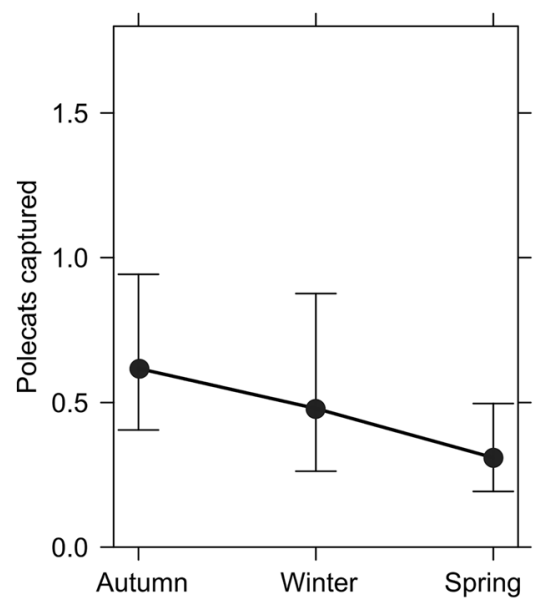

b

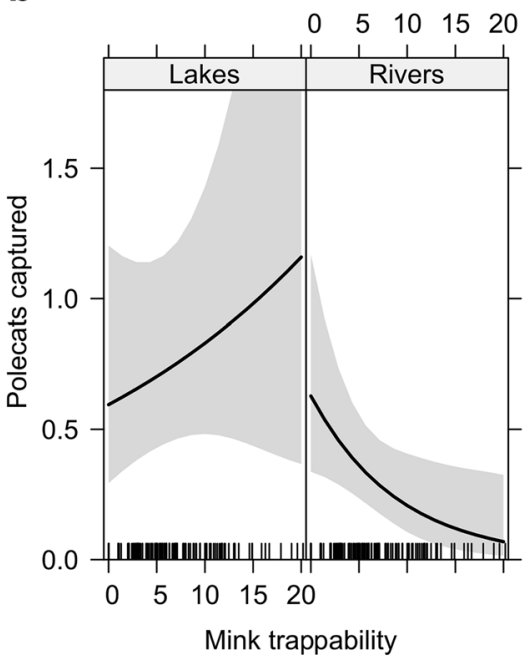

C

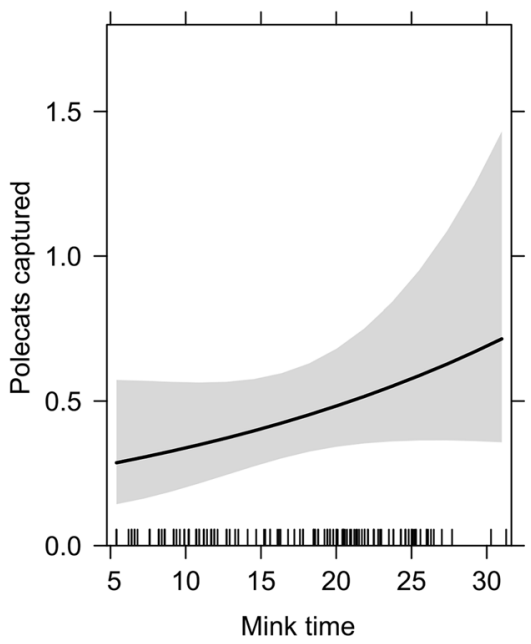

Fig. 3 The effects of season (a), mink density at rivers and lakes (b), and time that has elapsed since mink colonization on the number of trapped polecats $(\mathbf{c})$

"North". There was a positive correlation between the number of mink and polecats shot annually in Poland (Fig. 5).

\section{Discussion}

In our analyses, we attempted to find evidence of spatial segregation of the European polecat and American mink by analysing their abundances along river and lake banks. We also tried to determine the population trends of both species using hunting bag records. The obtained data revealed some basic information about polecat and mink densities and distribution. In general, the results of our study show that at a large geographical scale population of both these mustelids can coexist. However, in our opinion, data from live-trapping and hunting bag records are insufficient to identify the polecat's precise long-term population trends and habitat selection in response to competitive interactions with the invasive mink.

Table 1 Summary of GLMM model explaining number of polecats trapped at 60 sites in Poland, in relation to mink trappability, time (years) that had elapsed since mink colonisation, water body type

\section{Indices of polecat and mink density}

In the regions invaded by mink, indices of mink density were about tenfold higher than those of polecat density. This result, based on a large sample of captured animals, clearly showed that in riparian habitats, mink outnumbered polecats; however, it is not obvious how this large disproportion should be interpreted. In riparian habitats densely populated by mink, interspecific competition is expected to limit polecat numbers. In Belarus, in areas colonized by mink, polecat density declined 2.5-fold and mink density increased 3.5-fold after a few years (Sidorovich and Macdonald 2001; Sidorovich et al. 2008). In Catalonia, trappability of polecats decreased after mink colonized the region, but other indices of polecat abundance did not show decreasing trends (Melero et al. 2012). On the other hand, in the UK, the polecat's range has continued to expand despite the mink being widespread over most of the country (Croose 2016). The results of our study show that the number of polecats captured at rivers decreased

(WBT; river or like), season (winter, spring and autumn), and interaction between mink trappability and waterbody type. Significant effects are marked with asterisks

\begin{tabular}{lrrrr}
\hline Variables & Estimate & SE & Z value & P value \\
\hline Intercept & -5.2943 & 0.5617 & -9.425 & $<2 \mathrm{e}-16$ \\
Mink trappability & 0.0350 & 0.0398 & 0.880 & 0.3786 \\
Time since mink colonisation & 0.0436 & 0.0239 & 1.821 & 0.0685 \\
WBT (River) & -0.0454 & 0.4408 & -0.103 & 0.9180 \\
Season (Spring) & -0.7142 & 0.2713 & -2.632 & 0.0085 \\
Season (Winter) & -0.2819 & 0.3433 & -0.821 & 0.4115 \\
Mink trappability: WBT (River) & -0.1427 & 0.0640 & -2.228 & 0.0259 \\
\hline
\end{tabular}



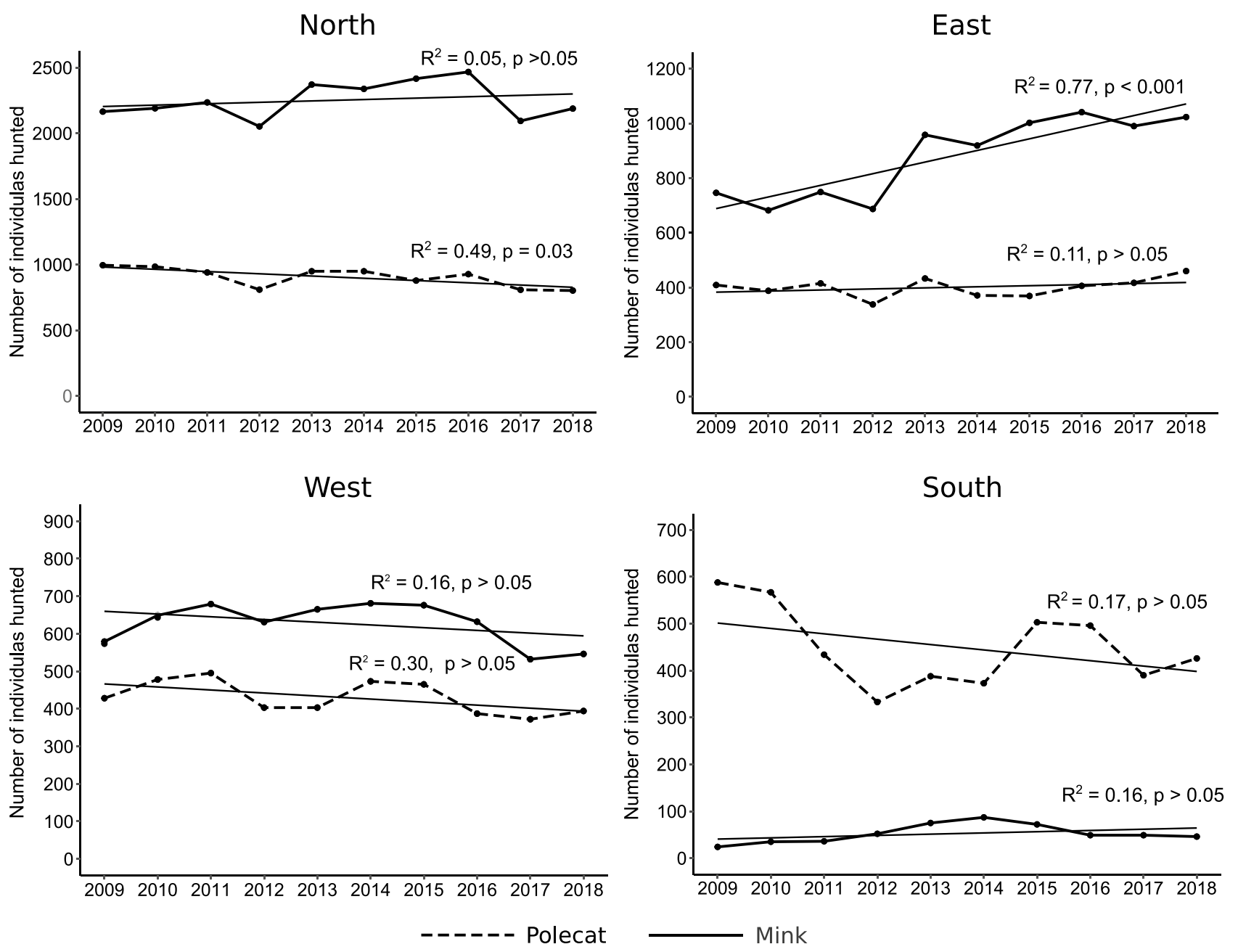

Fig. 4 Number of polecats and mink hunted in four regions of Poland in the years 2009-2018

with increasing indices of mink density. This suggests that polecats use riparian habitats along river banks less often when mink are abundant.

Polecats and mink share many of the same environmental resources (food, shelters); however, their niche overlap is difficult to determine precisely, as both species easily change their food and habitat preferences. Studies have shown that polecat and mink home ranges can overlap, but mostly in the vicinity of water bodies (Harrington and Macdonald 2008; Brzeziński et al. 2010a, b); core areas are always separate, and individuals avoid being close to one another. Moreover interspecific competition between polecat and mink can be reduced due to temporal partitioning of habitats used by both species (Lodé 1993; Harrington and Macdonald 2008; Brzeziński et al. 2010a, b).

We found polecats to be less numerous in riparian habitats than mink. This observation may have been because polecats use two-dimensional space including alderwoods, meadows, fields and rural habitats far from waterbodies, in contrast to mink, which are distributed linearly. This flexibility in habitat choice, which includes the option to use habitats distant from rivers and lakes, was supported by the differences in the proportions of polecats and mink trapped by us and those shot by hunters. Our live-trappings were conducted only along shorelines of rivers and lakes, whereas hunters hunt in a variety of habitats, often far from waterbodies. Assuming hunters shoot polecats and mink randomly and opportunistically as non-target species, the significantly higher proportion of polecats shot $(36.4 \%)$ then trapped (8.2\%) suggests that this mustelid was four times more abundant in various habitats away from river and lake banks (landscape scale) than in riparian habitats (one habitat scale). Therefore, we agree with Harrington and Macdonald (2008) that the restriction of the American mink to linear habitats along river and lake banks may partition the niches of these mustelids sufficiently for them to coexist. Interestingly, our results showed that at lake banks, there was no relation between the number of captured polecats and mink density. It seems that lake surroundings are refugia for polecats, where the mink's competitive impact is lower, despite 


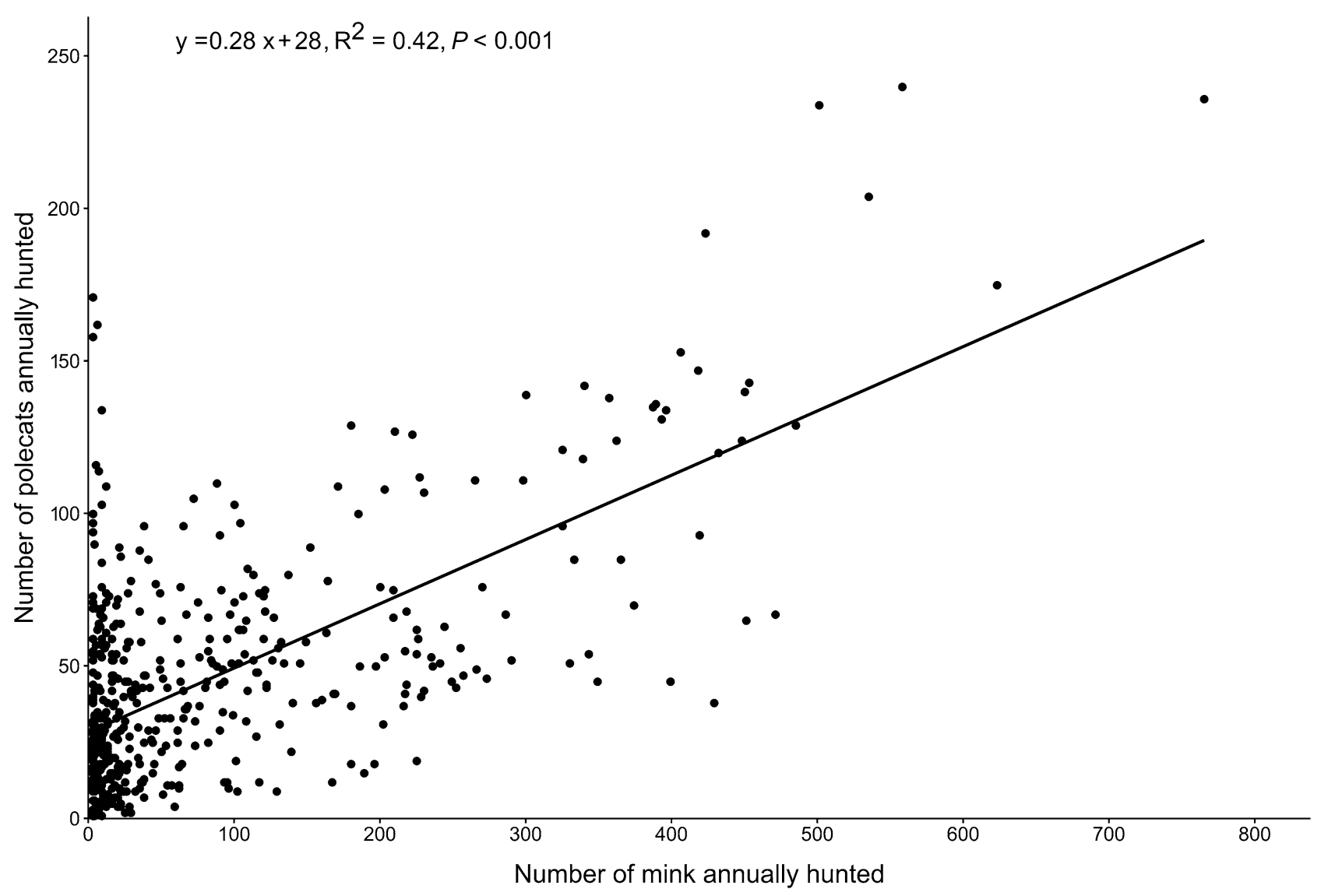

Fig. 5 Correlation between the number of polecats and mink killed in hunting districts in the years 2009-2018

there being no difference in mink density between rivers and lakes (Brzeziński et al. 2019). This may be because lakes adjoin more complex habitats than river banks (for example alderwoods), as human activities have probably degraded river valleys more severely than the vicinities of lakes (however, there were no data available to carry out such a comparison).

\section{Polecat and mink sex ratio}

In populations of small mustelids, males outnumber females regardless of the sampling method, but this disproportion does not necessarily reflect the real sex ratio; rather, it mostly results from the larger mobility and larger home ranges of males compared to females. For example, in Denmark, polecat males comprised about $67 \%$ of all individuals sampled in all age groups (Kristiansen et al. 2007), and in Luxemburg, among polecat road casualties, males comprised 76\% (Baghli and Verhagen 2003). Mustelids can exhibit particularly skewed sex ratios in trap captures because males encounter traps more often (Buskirk and Lindstedt 1989). In our study, males comprised about $80 \%$ of all polecats trapped. We also caught more mink males than females, but the proportion was more balanced: males comprised about $65 \%$ of all captured individuals. Archival data collected by the Mammal Research Institute PAS in Białowieża show that in Poland in the 1960-1970s (i.e. in the period prior to the mink invasion), the polecat sex ratio was less skewed towards males (males $61 \%, n=651$ ) than recently and was more similar to that found by us in mink. These results may confirm the finding of Barrientos (2015) that in the presence of American mink, the polecat sex-ratio is more skewed towards males. Due to the few polecats captured at sites with no mink (five sites), we were not able to compare polecat sex ratios in areas occupied and unoccupied by mink. But comparing the polecat sex ratios in the periods before and after the mink invasion, as well as the differences between the sex ratios of captured mink and polecats, suggests that the proportion of males and females in the polecat population may have changed. On the other hand, this difference may result from the mostly unknown origin of polecats collected in the past (hunted, trapped, traffic casualties etc.).

To what extent the male-skewed sex ratio negatively affects female reproduction and population persistence is not clear. Increased mortality in female polecats could be linked to competition with the invasive mink, contributing 
to the distortion of the sex ratio in native species, and thus affecting population productivity and dynamics (Barrientos 2015). However, even if is true that the polecat sex-ratio is more skewed towards males in the presence of American mink, the lower number of reproductive females would not necessarily negatively affect population productivity and density, as females living in low densities can have a higher reproductive output than those living in higher ones (Rödel et al. 2004). Mink are abundant mostly along the banks of waterbodies, and they are distributed linearly, whereas polecats also inhabit areas distant from waterbodies. Thus, even if mink compete with polecats, and even if this competition leads to lower survival of polecat females, this interaction may only occur in a relatively small portion of the polecat range, with most polecats (including females) not having to compete with mink. These spatial interactions are different from those between American and European mink, whose habitat niches are more similar (Sidorovich 1999, 2001). In our study, we did not find evidence that the mink invasion has caused the polecat population to decline, nor that interspecific competition with mink reduces polecat reproduction rates.

\section{Hunting bag records}

Hunting bags are an indirect and imprecise method of estimating game numbers (Ranta et al. 2008); however, they are frequently used to study population dynamics (e.g. Merli and Meriggi 2006; Robertson et al. 2017). For example, in Luxemburg, hunting records (years 1955-2000) revealed a strong decrease in the number of polecats killed over time, suggesting a population decline (Baghli and Verhagen 2003). In Poland, polecat population dynamics during the initial period of mink colonization (1980-2000) remain unknown, as there are no reliable hunting bag records or any other data available for this period. According to the hunting bag records for the period 2009-2018, the number of polecats shot has not varied significantly, showing only a slight declining trend. Moreover, there was little variation in polecat bag trends among regions, and in the mean number of polecats killed annually per $1000 \mathrm{~km}^{2}$. This is despite the abundances of mink, as measured by the hunting bag records, differing significantly, particularly between northern and southern Poland. In the northern part of the country, large mink hunting bags reflect high mink abundance, which results from the high density of rivers and lakes in this region (Brzeziński et al. 2019). Thus, although using hunting bag data as indices of population dynamics requires caution, it is highly probable that polecat population density in Poland has not declined over the last decade. Based on this result, we can conclude that recently, none of the potentially negative factors (e.g. changes in land use, increased traffic load) has been affecting polecats more severely than in the past.
Mink abundance has also likely not reduced polecat numbers since 2009 , as polecat population dynamics have not differed between regions with high and low mink densities.

\section{Interspecific competition and its impact on the polecat population}

Although interspecific competition between the polecat and mink is widely accepted, it is not clear whether mink are dominant in polecat-mink interactions. Some studies suggest that polecat populations may be negatively affected by expanding mink populations (Sidorovich and Macdonald 2001; Sidorovich et al. 2008; Melero et al. 2012), while several others indicate that both species can coexist in an area (Lodé 1993; Hammershøj et al. 2004; Harrington and Macdonald 2008; Brzeziński et al. 2010a, b). In the UK, in the presence of otters and polecats, mink body condition decreased and mink altered aspects of their behaviour (diet, daily activity) (Harrington et al. 2009); however, the authors were unable to attribute these morphological and behavioural shifts to one or the other native species. In general, the coexistence of the polecat and mink probably depends on habitat heterogeneity and the degree of niche segregation (Melero et al. 2012). Polecats are not as restricted to riparian habitats as mink (Lodé 1993; Harrington and Macdonald 2008; Brzeziński et al. 2010a, b), enabling them to respond to changing food availability and competition with mink. In areas with diverse types of waterbodies (rivers, streams, oxbows, midfield ponds, ditches etc.), habitat niche separation between the polecat and mink can be pronounced, with the polecat being more abundant along small water courses or wetlands and mink inhabiting the vicinity of medium and large rivers (Lodé 1993; Sidorovich et al. 1996), and this separation may reduce the impact of the American mink. For example, in Białowieża Forest, polecats prefer to settle along smaller watercourses whereas mink are more abundant at larger rivers (Sidorovich et al. 1996). However, it is unknown to what extent the current distribution of the species results from their past interspecific competition and how polecats were distributed in the forest prior to the mink invasion in the late 1970s. In summary, although the habitat and trophic niches of both species partly overlap, and thus the polecat and mink compete for the same environmental resources, in heterogeneous landscapes, their populations probably spatially segregate enough for the polecat to coexist with the American mink. However, even if the mink forces a habitat switch in polecats (i.e. their withdrawal from riparian habitats, mostly at rivers), it remains a mystery how this affects the polecat population.

Although the key environmental factors that affect polecat and mink abundance are known, the interactions between these two mustelids may be more complex than discussed thus far, going beyond food and habitat niche 
overlap. For example, the American mink contributes to the maintenance of the life cycle of some pathogens (helminthes and diseases), which may have implications for the conservation of native mustelids (Torres et al. 2008; Kołodziej-Sobocińska et al. 2018, 2020; Zalewski et al. 2021b); however, still not much is known about the interspecific transfer of parasites and pathogens between the mink and polecat (especially the Aleutian mink disease parvovirus).

\section{Conclusions}

The only available large-scale and long-term (10-20 years) data that we could use to analyse European polecat and American mink abundance and their interspecific interactions in Poland came from live-trapping and hunting bag records. Although both datasets were based on large samples, we found them inadequate for showing evidence of the competitive interactions between the polecat and mink. Consequently, the negative impact of the invasive mustelid on the native one could neither be confirmed nor excluded. We found weak evidence that polecats in Poland have declined since the country was colonized by American mink, and 40 years after the beginning of mink invasion, the polecat still occurs at a landscape scale. However, it must be emphasized that we lack data on polecat densities prior to the mink invasion, and our analysis covered a period after the mink population was already established across most of the country. Our data shed some light on polecat-mink interactions and primarily provide a background for future research by showing how difficult analysing and interpreting this type of data can be. In our opinion, more research is needed on the population dynamics of polecat and mink to clarify the possible interactions between these two mustelids. We agree with Harrington and Macdonald (2008) who suggested that future research on interspecific competition should focus on the question of whether the carrying capacity of the landscape (not only of riparian habitats) for polecats varies with mink abundance, and perhaps an experimental design may be needed to fill these knowledge gaps.

Supplementary Information The online version contains supplementary material available at https://doi.org/10.1007/s10344-021-01511-4.

Author contribution Marcin Brzeziński and Andrzej Zalewski conceived the ideas and collected the data; Andrzej Zalewski and Aleksandra Zarzycka analysed the data; Marcin Brzeziński, Andrzej Zalewski and Tom A. Dierens led the writing of the manuscript. All the authors contributed critically to the drafts and gave final approval for publication.

Funding Partial financial support was received from the National Science Centre, Poland (Grant No: 2013/09/B/NZ8/03339).
Data availability The datasets used and analysed during the current study are available from the corresponding author on reasonable request.

\section{Declarations}

Ethics approval All animal capture and handling procedures were approved by the Ministry of Environment, Regional Directorate for Environmental Protection and Local Ethics Committee for Animal Experiments.

Conflict of interest The authors declare no competing interests.

Open Access This article is licensed under a Creative Commons Attribution 4.0 International License, which permits use, sharing, adaptation, distribution and reproduction in any medium or format, as long as you give appropriate credit to the original author(s) and the source, provide a link to the Creative Commons licence, and indicate if changes were made. The images or other third party material in this article are included in the article's Creative Commons licence, unless indicated otherwise in a credit line to the material. If material is not included in the article's Creative Commons licence and your intended use is not permitted by statutory regulation or exceeds the permitted use, you will need to obtain permission directly from the copyright holder. To view a copy of this licence, visit http://creativecommons.org/licenses/by/4.0/.

\section{References}

Ahlers AA, Heske EJ, Schooley RL (2016) Prey distribution, potential landscape supplementation, and urbanization affect occupancy dynamics of American mink in streams. Landscape Ecol 31:1601-1613

Baghli A, Verhagen R (2003) The distribution and status of the polecat Mustela putorius in Luxemburg. Mammal Rev 33:57-68

Baghli A, Walzberg C, Verhagen R (2005) Habitat use by the European polecat Mustela putorius at low density in a fragmented landscape. Wildlife Biol 11:331-339

Barrientos R (2015) Adult sex-ratio distortion in the native European polecat is related to the expansion of the invasive American mink. Biol Conserv 186:28-34

Bertolino S, di Montezemolo NC, Bassano B (2009) Food-niche relationships within a guild of alpine ungulates including an introduced species. J Zool 277:63-69

Berzins R, Ruette S (2014) Status of the polecat Mustela putorius (Linnaeus, 1758) in France and management implications. Munibe Monographs Nature Series 3:101-108

Blandford PRS (1987) Biology of the polecat Mustela putorius: a literature review. Mammal Rev 17:155-198

Bonesi L, Chanin P, Macdonald DW (2004) Competition between Eurasian otter Lutra lutra and American mink Mustela vison probed by niche shift. Oikos 106:19-26

Bonesi L, Palazon S (2007) The American mink in Europe: Status, impacts, and control. Biol Conserv 134:470-483

Brzeziński M, Ignatiuk P, Żmihorski M, Zalewski A (2018) An invasive predator affects habitat use by native prey: American mink and water vole co-existence in riparian habitats. J Zool 304:109-116

Brzeziński M, Jędrzejewski W, Jędrzejewska B (1992) Winter home ranges and movements of polecats Mustela putorius in Białowieża Primeval Forest, Poland. Acta Theriol 37:181-191

Brzeziński M, Marzec M, Żmihorski M (2010a) Spatial distribution, activity, habitat selection of American mink (Neovison vison) and 
polecats (Mustela putorius) inhabiting the vicinity of eutrophic lakes in NE Poland. Folia Zool 59:183-191

Brzeziński M, Natorff M, Zalewski A, Żmihorski M (2012) Numerical and behavioral responses of waterfowl to the invasive American mink: A conservation paradox. Biol Conserv 147:68-78

Brzeziński M, Romanowski J, Żmihorski M, Karpowicz K (2010b) Muskrat (Ondatra zibethicus) decline after expansion of American mink (Neovison vison) in Poland. Eur J Wildlife Res 56:341-348

Brzeziński M, Święcicka-Mazan A, Romanowski J (2008) Do otters and mink compete for access to foraging sites? A winter case study in the Mazurian Lakeland, Poland. Ann Zool Fenn 45:317-322

Brzeziński M, Żmihorski M, Nieoczym M, Wilniewczyc P, Zalewski A (2020) The expansion wave of an invasive predator leaves declining waterbird populations behind. Divers Distrib 26:138-150

Brzeziński M, Żmihorski M, Zarzycka A, Zalewski A (2019) Expansion and population dynamics of a non-native invasive species: the 40-year history of American mink colonisation of Poland. Biol Invasions 21:531-545

Buskirk SW, Lindstedt SL (1989) Sex biases in trapped samples of Mustelidae. J Mammal 70:88-97

Costa M, Fernandes C, Santos-Reis M (2014) Ecology and conservation of the polecat Mustela putorius (Linnaeus, 1758) in Portugal: a review. Munibe Monographs Nature Series 3:79-87

Croose E (2016) The distribution and status of the polecat (Mustela putorius) in Britain 2014-2015. The Vincent Wildlife Trust

Croose E, Duckworth JW, Ruette S, Skumatov DV, Kolesnikov VV, Saveljev AP (2018) A review of the status of the Western polecat Mustela putorius: a neglected and declining species? Mammalia 82:550-564

Doherty TS, Glen AS, Nimmo DG, Ritchie EG, Dickman CR (2016) Invasive predators and global biodiversity loss. PNAS 113:11261-11265

Fournier P, Maizeret C, Jimenez D, Chusseau J-P, Aulagnier S, Spitz F (2007) Habitat utilization by sympatric European mink Mustela lutreola and polecats Mustela putorius in south-western France. Acta Theriol 52:1-12

Hammershøj E, Thomsen EA, Madsen B (2004) Diet of free-ranging American mink and European polecat in Denmark. Acta Theriol 49:337-347

Hardin G (1960) The competitive exclusion principle. Science 131:1292-1297

Harrington LA, Harrington AL, Yamaguchi N, Thom MD, Ferreras P, Windham TR, Macdonald DW (2009) The impact of native competitors on an alien invasive: temporal niche shifts to avoid interspecific aggression? Ecology 90:1207-1216

Harrington LA, Macdonald DW (2008) Spatial and temporal relationships between invasive American mink and native European polecats in the Southern United Kingdom. J Mammal 89:991-1000

Hofmeester TR, Dijkstra V, Dekker JJA, vad der Meij T, Broekhuizen S (2019) The status of the Dutch polecat population: correction of a recently published error. Mammalia 83:453-454

Institute of Nature Conservation PAS (2010) Atlas of Polish Mammals. https://www.iop.krakow.pl/Ssaki/gatunek/109

Jędrzejewska B, Sidorovich VE, Pikulik MM, Jędrzejewski W (2001) Feeding habits of the otter and the American mink in Białowieża Primeval Forest (Poland) compared to other European populations. Ecography 24:165-180

Jędrzejewski W, Jędrzejewska B, Brzeziński M (1993) Winter habitat selection and feeding habits of polecats (Mustela putorius) in the Białowieża National Park, Poland. Z Saugetierkd 58:75-83

Kołodziej-Sobocińska M, Brzeziński M, Niemczynowicz A, Zalewski A (2018) High parasite infection level in non-native invasive species: it is just a matter of time. Ecography 41:1283-1294

Kołodziej-Sobocińska M, Dvorožňáková E, Hurníková Z, Reiterová K, Zalewski A (2020) Seroprevalence of Echinococcus spp. and
Toxocara spp. in invasive non-native American mink. EcoHelth $17: 13-27$

Kristiansen LV, Sunde P, Nachman G, Madsen AB (2007) Mortality and reproductive patterns of wild European polecats Mustela putorius in Denmark. Acta Theriol 52:371-378

Lanszki J, Heltai M (2007) Diet of the European polecat and the steppe polecat in Hungary. Mammalian Biol 72:49-53

Le Louarn M, Couillens B, Deschamps-Cottin M, Clergeau P (2016) Interference competition between an invasive parakeet and native bird species at feeding sites. J Ethol 34:291-298

Lodé T (1993) Diet composition and habitat use of sympatric polecat and American mink in western France. Acta Theriol 38:161-166

Lodé T (1994) Environmental factors influencing habitat exploitation by polecat Mustela putorius in western France. J Zool 234:75-88

Lodé T (1997) Trophic status and feeding habits of the European polecat Mustela putorius L. 1758. Mammal Rev 27:177-184

Malecha AW, Antczak M (2013) Diet of the European polecat Mustela putorius in an agricultural area in Poland. Folia Zool 62:48-53

Melero Y, Palazón S, Revilla E, Martelo J, Gosàlbez J (2008) Space use and habitat preferences of the invasive American mink (Mustela vison) in a Mediterranean area. Eur J Wildlife Res 54:609-617

Melero Y, Plaza M, Santulli G, Saavedra D, Gosàbez J, Ruiz-Olmo J, Palazón S (2012) Evaluating the effect of American mink, an alien invasive species, on the abundance of a native community: is coexistence possible? Biodivers Conserv 21:1795-1809

Merli E, Meriggi A (2006) Using harvest data to predict habitat population relationship of the wild boar Sus scrofa in Northern Italy. Acta Theriol 51:383-394

Niemczynowicz A, Świętochowski P, Brzeziński M, Zalewski A (2017) Non-native predator control increases the nesting success of birds: American mink preying on wader nests. Biol Conserv 212:86-95

Peck HL, Pringle HE, Marshall HH, Owens IPF, Lord AM (2014) Experimental evidence of impacts of an invasive parakeet on foraging behavior of native birds. Behav Ecol 25:582-590

Pianka ER (1974) Niche overlap and diffuse competition. P Natl Acad Sci USA 71:2141-2145

Polo-Cavia N, López P, Martín J (2011) Aggressive interactions during feeding between native and invasive freshwater turtles. Biol Invasions 13:1387-1396

Pucek Z, Raczyński J (1983) Atlas of Polish mammals. PWN-Polish Scientific Publishers

Ranta E, Lindström J, Lindén H, Helle P (2008) How reliable are harvesting data for analyses of spatio-temporal population dynamics? Oikos 117:1461-1468

R Core Team (2020) R: a language and environment for statistical computing. R Foundation for Statistical Computing, Vienna, Austria. https://www.R-project.org/

Robertson GS, Aebischer NJ, Baines D (2017) Using harvesting data to examine temporal and regional variation in red grouse abundance in the British uplands. Wildlife Biol 2017:1-11. https://doi.org/ 10.2981/wlb.00276

Roger M (1991) Food-habits and prey availability in the polecat Mustela putorius. Rev Ecol-Terre Vie 46:245-261

Rödel HG, Bora A, Kaiser J, Kaetzke P, Khaschei M, von Holst D (2004) Density-dependent reproduction in the European rabbit: a consequence of individual response and age-dependent reproductive performance. Oikos 104:529-539

Sainsbury KA, Shore RF, Schofield H, Croose E, Pereira MG, Sleep D, Kitchener AC, Hantke G, McDonald RA (2018) Long-term increase in secondary exposure to anticoagulant rodenticides in European polecats Mustela putorius in Great Britain. Environ Pollut 236:689-698

Sainsbury KA, Shore RF, Schofield H, Croose E, Campbell RD, McDonald RA (2019) Recent history, current status, conservation and management of native mammalian carnivore species in Great Britain. Mammal Rev 49:171-188 
Salo P, Korpimäki E, Banks PB, Nordström M, Dickman CR (2007) Alien predators are more dangerous than native predators to prey populations. Proc Roy Soc B 274:1237-1243

Santos MJ, Matos HM, Baltazar C, Grilo C, Santos-Reis M (2009) Is polecat (Mustela putorius) diet affected by "mediterraneity"? Mammalian Biol 74:448-455

Sax DF, Stachowicz JJ, Brown JH, Bruno JF, Dawson MN, Gaines SD, Grosberg RK, Hastings A, Holt RD, Mayfield MM, O'Connor MI, Rice WR (2007) Ecological and evolutionary insights from species invasions. Trends Ecol Evol 22:465-471

Shore RF, Birks JDS, Freestone P (1999) Exposure of non-target vertebrates to second-generation rodenticides in Britain, with particular reference to the polecat Mustela putorius. New Zeal J Ecol 23:199-206

Sidorovich VE (2000) Seasonal variation in the feeding habits of riparian mustelids in river valleys of NE Belarus. Acta Theriol 45:233-242

Sidorovich VE, Jędrzejewska B, Jędrzejewski W (1996) Winter distribution and abundance of mustelids and beavers in the river valleys of Białowieża Primeval Forest. Acta Theriol 41:155-170

Sidorovich VE, Kruuk H, Macdonald DW (1999) Body size, and interactions between European and American mink (Mustela lutreola and M. vison) in Eastern Europe. J Zool 248:521-527

Sidorovich VE, Macdonald DW (2001) Density dynamics and changes in habitat use by the European mink and other native mustelids in connection with the American mink expansion in Belarus. Neth J Zool 51:107-126

Sidorovich VE, Sidorovich AA, Ivanovskij VV, Pikulik MM, Shinkevich EP (2008) The structure of vertebrate predator community in northeastern Belarus before and after naturalization of the American mink and raccoon dog. Folia Zool 57:373-391

Sidorovich VE, Polozov AG, Zalewski A (2010) Food niche variation of European and American mink during the American mink invasion in north-eastern Belarus. Biol Invasions 12:2207-2217
Torres J, Miquel J, Fournier P, Fournier-Chambrillon C, Liberge M, Fons R, Feliu C (2008) Helminth communities of the autochthonous mustelids Mustela lutreola and M. putorius and the introduced Mustela vison in south-western France. J Helminthol $82: 349-355$

Virgós E (2003) Association of the polecat Mustela putorius in eastern Spain with montane pine forests. Oryx 37:484-487

Weber D (1989a) Foraging in the polecats Mustela putorius L. in Switzerland: the case of a specialist anuran predator. Z Saugetierkd $54: 377-392$

Weber D (1989b) The diet of polecat (Mustela putorius L.) in Switzerland. Z Saugetierkd 54:157-171

Weber D (1989c) The ecological significance of resting sites and the seasonal habitat change in polecats Mustela putorius. J Zool 217:629-638

Weber J-M, Aubry S, Ferrari N, Fischer C, Lachat Feller N, Meia J-S, Meyer S (2002) Population changes of different predators during a water vole cycle in a central European mountainous habitat. Ecography 25:95-101

Zabala J, Zuberogoitia I, Martínez-Climent JA (2005) Site and landscape features ruling the habitat use and occupancy of the polecat (Mustela putorius) in a low density area: a multiscale approach. Eur J Wildlife Res 51:157-162

Zalewski A, Szymura M, Kowalczyk R, Brzeziński M (2021a) Low individual diet variation and high trophic niche overlap between the native polecat and invasive American mink. J Zool 314:151-161

Zalewski A, Virtanen JME, Brzeziński M, Kołodziej-Sobocińska M, Jankow W, Sironen T (2021b) Aleutian mink disease: Spatio-temporal variation of prevalence and influence on the feral American mink. Transbound Emerg Dis. https://doi.org/10.1111/tbed.13928

Publisher's Note Springer Nature remains neutral with regard to jurisdictional claims in published maps and institutional affiliations. 